Article

\title{
Reflections upon the Privacy in the Converged Commercial Radio: A Case Study of Royal Prank
}

\author{
Grażyna Stachyra \\ Institute of Communication and Media Studies, Maria Curie-Skłodowska University, 20-080 Lublin, Poland; \\ E-Mail: grazyna.stachyra@poczta.umcs.lublin.pl
}

Submitted: 15 January 2020 | Accepted: 11 May 2020 | Published: 23 June 2020

\begin{abstract}
This article focuses on the problematic consequences of shifting boundaries of converged radio practices for individual privacies. Holding that privacy is constructed through the interrelated information practices of both individuals and their mediated surroundings, it addresses radio as a previously intimate and privacy friendly medium. The case of the Royal Prank call by the Australian 2DayFM radio station demonstrates how contemporary converged radio practices affect the privacies of unintended participants in their shows. In December 2012, Jacintha Saldanha, nurse of London's Royal King Edward VII Hospital committed suicide after two Australian radio presenters had made a prank phone call pretending to be Queen Elizabeth and Prince Charles concerned about the state of Duchess Kate's health, who was expecting her first child. The case identifies three conditions, each with implications on privacy. First, digitization renders radio content archivable and repeatable. There is a second life of radio programs keeping available information about any people involved. Secondly, the division of radio related labour leads to a lack of journalistic responsibility for respecting privacy standards. Broadcasters feel no need to be sensitive regarding the consequences of disseminated material, as commercial and legal staff decide on that. Finally, legal frameworks continue to apply legacy radio privacy measures and do not correspond to these new working conditions, as the reactions of the Australian supervisory authority show. In consequence, the case of the Royal Prank call demonstrates the impossibility to fight individual privacy when one is unintentionally involved in radio shows.
\end{abstract}

\section{Keywords}

commercial radio; convergence; media supervision; privacy; radio station; radio show; Royal Prank

\section{Issue}

This article is part of the issue "The Politics of Privacy: Communication and Media Perspectives in Privacy Research" edited by Johanna E. Möller (Johannes Gutenberg University Mainz, Germany), Jakub Nowak (Maria Curie-Sklodowska University, Poland), Sigrid Kannengießer (University of Bremen, Germany) and Judith E. Möller (University of Amsterdam, The Netherlands).

(C) 2020 by the author; licensee Cogitatio (Lisbon, Portugal). This article is licensed under a Creative Commons Attribution 4.0 International License (CC BY).

\section{Theory}

The convergence of radio with other digital media was a revolutionary process that evoked substantial changes in radio production. The outline of any new concepts of privacy (not yet fully defined) emerged as part of these changes.

When radio broadcasting was first introduced in the early 1920s, the broadcast signals did not stop at national borders. An increasing number of listeners were soon enjoying programs from far away (Ala-Fossi, 2016, p. 280), "but when TV was introduced after WWII, it was in practice a 'medium without a public"' (Fickers, 2006, pp. 16-18). The competition for the auditorium had begun. Over the years, the radio had lost its monopoly status, but its essence remained untouched.

In the following decades new technologies emerged (i.e., satellite radio, internet), so the radio signal found new transmission channels and flowed via fibre-optic cable. The media convergence (Jenkins, 2008) turned out to be a real revolution for the radio. It changed the way of radio communication and brought the radio onto the path of online technology. Radio websites became a tool for providing extended information on the regulations 
of competitions, awards, radio people, the history of radio stations, etc. Radio stations started to visualise fragments of the program and put them online. Gradually, broadcasters began to publish recorded fragments of programs online, whereas podcasts were born.

Convergence was quite broadly described by R. Silverstone, who pointed out several of its aspectsfrom technological innovation to 'consequential convergence in patterns of use' by consumers (Silverstone, 1995, p. 11). Many studies have invoked this convergence concept, as they have analysed changes in news production practices within media organisations of which they are "seeking to distribute across different media platforms" (Preston \& Rogers, 2013, p. 249), including the implications for the status of journalists (Preston, 2009). The concept of convergence implies a blurring of the distinctions between what were previously separate communication services and functions (de Sola Pool, 1983). Convergence as the "combination of technologies, products, staff and geography amongst the previously distinct provinces of print, television and online media" (Singer, 2004, p. 3), opened the space for 'transmedia storytelling.' The term primarily identified in the 1990s (by authors in different areas), was coined by Henry Jenkins (2003) as a process "where integral elements of a fiction get dispersed systematically across multiple delivery channels to create a unified and coordinated entertainment experience" (Sousa, Martins, \& Zagalo, 2016, p. 119). That is why the content accessible by portable devices over the mobile Internet can be considered in a quite literal sense as 'remediated' by one medium in another (Dwyer, 2015, p. 17). Convergent media industries are merging and diffusing across media platforms together with their transmedia audiences, using multiple screen devices and mobile interfaces (Dwyer, 2015, p. 13) The media content is often 'optimised' for the web, modified for being accessed by mobile devices according to the motto: "Choose the best media to launch a story and the best flow between media" (Meier, 2007, p. 7).

For the radio one of the new ways to 'flow between media' meant the birth of the podcast. The term 'podcasting' was introduced in 2004 by the BBC journalist Ben Hammersley (Bonini, 2015, pp. 21-30). Podcasting is both producing podcasts (audio files, sometimes also video), as well as the technology to download them via an RSS reader. This allows the storage of podcasts on a computer, MP3 player, or mobile phone using free software such as iTunes or Juice. Podcasts migrated from radio. The BBC was a pioneer of this trend in 2004, making fragments of radio programs (podcasts) available on the BBC website. Podcasts can be listened to with a time shift (Dubber, 2013, p. 58). Todd Cochrane describes podcasting as "walkaway content" operating outside of the radio (Berry, 2006, p. 145). Siobhan McHugh $(2012$, p. 40) views podcasting as the incarnation of radio narrative forms. Richard Berry (2016, p. 5) claims that podcasts should be considered as radiogenic practices or occurring within the radio industry. Some online stations broadcast short cyclic episodes of programs and call them podcasts. In most cases however, radio stations place podcasts on their websites or podcast platforms.

Podcasting has brought many benefits to radio listeners, but "the human being is not quasi-automatically 'prepared' for the effects of every new technology" (Köchler, 2017 , p. 9). Podcasting changed the perception of people's privacy. Modern radio is a part of the integrated media industry, in which the attractiveness of content is a primary goal and the possible violation of third-party privacy is part of the cost. Radio is winning the 'game of privacy' played between the media, public figures, politicians, and celebrities. The media need attractive protagonists in the public sphere. Likewise, they also need the media to exist in a public sphere. The problem with the privacy limitations is that those limits are very fluid and not defined properly. There is sort of 'grey area,' where the privacy of some actors is not properly protected. They become the victims of 'collateral damage,' as a result of the game that the media industry plays with public figures and the audience. This article illustrates one of such cases.

\section{Transformations of the Radio as the Private Medium}

The first explicit articulation of privacy was connected with media. As photography was emerging, whereby opening possibilities for publicising the private image of people via newspapers, Samuel Warren and Louis Brandeis in 1890 defined privacy as the right to "being left alone" or "being free from intrusion" (Tavani, 2013, p. 135). Gradually however, interpretations of intrusion concerned the right to determine what others should know about someone, control the possibility of identifying a given entity by others, and finally "one's ability to restrict access to and control the flow of one's personal information" (Ess, 2013, p. 72; Tavani, 2013, p. 136). Many researchers have shown that technology or politics have an impact on privacy. This is true, but apart from that there are certain business practices in the realm of journalism which can take away this control and violate the right to privacy.

It seems that the invention of the radio at the beginning of the 20th century guaranteed this control to the human being. Music, voices of announcers, and the theatre of imagination were introduced to the safe atmosphere of the private home. Because radio was a heavy piece of furniture, it was mainly listened to in the family circle. The 'radio at home' was associated with a specific broadcasting mode in which the value of the listener's comfort was simply receiving the broadcast. Habermas (1996) commented that:

The threshold separating the private sphere from the public is not marked by a fixed set of issues or relationships but by different conditions of communication. Certainly, these conditions lead to differences in the accessibility of the two spheres, safeguarding the 
intimacy of the one sphere and the publicity of the other. (p. 366)

That is why the radio strategy of building relationships was achieved by creating an atmosphere of closeness and uniqueness of the announcer's contact with the listeners. In the history of the radio, this stage can be called “intimacy radio" (Peters, 1997, pp. 5-16). In 1956 Donald Horton and Richard Wohl claimed "that while striving to build close relationships with the audience, the performers [via TV or radio] employed a mode of communicating 'for someone' by using devices such as rhetorical questions, voice modulation, or phrases of direct address" (Horton \& Wohl, 1956; Stachyra, 2017, p. 94). Although the radio reached an individual listener in remote parts of the world, it also evoked a sense of unity with other people listening to a specific program at the same time. It was therefore, a medium of both individual (private) and collective experience.

Gradually, radio's message resounded in factories (especially by mobilising workers during painstaking assembly-line work during WWII), or places of public utility. The 'exodus' of the radio from confined spaces was possible-from the 1960's - with the invention of transistor radio. Particularly in the US, the talk format began to gain popularity, promoting "ordinary topics" in radio discourse. Talk radio made headlines in the US in the mid1980s, when Howard Stern gained both fame and the nickname "shock jock" (Douglas, 2002, p. 486). At the end of the 1980's, the availability of mobile phones to private people increased rapidly. Contact with the radio had become easier than ever, so the broadcasters encouraged their audience to use many of new forms of contact. It resulted in more news and opinions, fast and often unverified news, and a growing number of 'prosumers.' Sensationalism appeared as a production trend in commercial stations. Controversial topics attracted the attention of listeners.

Access to mobile phones also facilitated the implementation of the joke-call genre, in which journalists (hosts, DJs, etc.) would call random or deliberately selected 'guests' and impersonate various people. They engaged the interlocutors in an intrigue which in the end simply means to be funny. The genre has a long radio history as it has been present on air since the 1940s, when the first gags in the series of Candid Microphone appeared. The entertainment convention of the prankcall (also called joke-call) promotes the journalists playing various roles and making a voice creation or preparation of a person's speech. These were the beginnings of radio tabloidization. The entertainment target began to justify the intrusion of a radio microphone into the safe sphere of a human being.

The consequence of radio-wide availability and broadcast duplicability on many platforms is a significant change in the context of privacy. On the analogue radio, the privacy of people appearing on air was obvious due to the lack of image (no recognition of the speaker's iden- tity), but also the one-time broadcast. On-air events did not remain in the listener's memory because they could not be repeated. On analogue radio, joke-calls sounded once. But the latest technologies and convergence contributed to the reproduction of jokes on the internet. What's more, presenters' behaviour became bolder according to the tabloid rule of sensationalism. In 1995, Canadian satirist journalist Pierre Brassard called Queen Elizabeth II, claiming to be Canadian Prime Minister Jean Chrétien. He persuaded her to record support for Canadian unity (the joke took place just before the separatist referendum of the Quebec province). The conversation was broadcast a few hours later on the Montreal radio CKOI FM as part of the satirical program Le Bleu Poudre. The palace called the prank "irritating and regrettable" (Lyall, 2012).

In 2003, two hosts of the Spanish-language radio WXDJ-FM in Florida, made a direct call to the president of Venezuela, Hugo Chavez. They provoked him to the alleged dialogue with the president of Cuba, Fidel Castro, whose voice was prepared from various media presentations. After a while, they revealed themselves and had fun on the air. What is more, a few months later, they did the same, this time calling Castro live and using the cooked-up statements of Chavez. When they appeared on air-they heard Castro's insults ("Miami radio fined for Castro hoax," 2004).

Convergence enabled the emigration of the Royal Prank 'outside' the radio to other media. That is why all the media almost simultaneously became recipients of the prank. The mediatised 'actor's' statements create the social context of the Royal Prank. Mediatisation is a set of transformations in the nature of contemporary social order, linked to the affordances and uses of media (Couldry, 2014). Therefore, the facts of the Royal Prank as the consequences of radio order under the convergence, the social context created by the 'actors' (entities) involved in this case and commercial radio legislation will be interpreted in this perspective.

Contemporary radio convergence makes the recordings (like those mentioned above) always available online. Search engines link to radio podcasts. We can say they 'immortalise' prank calls. It can be expected that constantly rediscovered joke-calls bring fans to radio stations. The heroes of the jokes mentioned above were public figures. But how strong is the 'right to be forgotten' in the case of civilians who are random heroes of the prank? The quote by Andrus Ansip, vice-president designate for the digital single market at the European Commission, sounds remarkable: "The European Court of Justice did not say that everybody has the right to be forgotten. 'Right to be forgotten' has to stay as an exception" (Dwyer, 2015, p. 47). This right is even more profound in the context of the accidental violation of privacy on the radio. This is due to the depersonalization of radio podcast production. Presenters must subordinate their behaviour to the overriding interests of the station. Even if it means an attempt on the privacy of third par- 
ties used in the recording. The Royal Prank is the case analysed here. It illustrates three factors that combined contribute to the present state of privacy protection in the modern radio: technology, production process, and insufficient legal regulations.

\section{The Case of the Royal Prank}

On December 2nd, 2012, Catherine, Duchess of Cambridge, was admitted to King Edward VII Hospital in London because of nausea. The media interest in this fact was enormous and somehow forced a statement by her husband Prince William, that the duchess was expecting their first child. On December 4th, at around 5:30 in the morning London time (GMT) and 4:30 p.m. Sydney time (AEST), the hosts of the Hot30 Countdown entertainment program of the Australian station 2DayFM, Mel Greig and Mike Christian, called the hospital claiming to be Queen Elizabeth II and the Prince of Wales ("Royal prank scandal," 2013). Nurse Jacintha Saldanha, who happened to be at the reception desk, answered the phone. There was no duty officer at the headquarters at night. Mel Greig overplaying a British accent asked for a conversation with Duchess Kate. Jacintha Saldanha herself did not reveal any secrets of the hospital or the patient, but switched the call to the nurse on duty with the Duchess, who provided confidential information about her health. Mike Christian joined the conversation, imitating the barking of corgi dogs, and then (as the Prince of Wales), asking when it would be possible to visit the Duchess in the hospital.

The joke was broadcast the next day (December 5th) with the consent of the station's lawyers. As a leading entertainment group, Southern Cross Austereo (SCA; 2DayFM's parent company), immediately spread the joke. The next day it was in the news headlines of all media in Australia and the world.

On December 7th, Jacintha Saldanha "was found hanged in her apartment in the nurses' quarter of the hospital in Marylebone, central London" (Laville \& Davies, 2012).

\section{The Method}

According to methods in contemporary media and communication research, many options for 'producing' content and distributing it result in "a complexity, a flux, and difficulties in how to capture it" (Kubitschko \& Kaun, 2016, p. vi). Thinking about the privacy transformations in contemporary radio, I have chosen the case study method as optimal. Although frequent criticism of case study methodology is that its dependence on a single case renders it incapable of providing a generalizing conclusion (Tellis, 1997), qualitative case studies are yet "an intensive, holistic description and analysis of a bounded phenomenon" (Miles \& Huberman, 1994, p. 25; Yazan, 2015 , p. 134). "It is a research strategy that focuses on understanding the dynamics present in a distinctive case" (Eisenhardt, 1989, p. 534).
According to Robert Yin's definition (2002, pp. 13-14), case is "a contemporary phenomenon within its real-life context"; an inquiry that investigates the case by addressing the 'how' or 'why' questions concerning the phenomenon of interest. Robert Stake and Robert Yin (Baxter \& Jack, 2008, p. 545) base themselves on a constructivist paradigm which is itself built upon the premise of social construction of reality (Searle, 1995). In general, constructivism seeks to explain how norms, principles, institutions, and discourses create social reality or, in other words, how these 'social contexts' affect social and political processes and, generally, the policymaking process. The basic premise of constructivism is that social reality is the result of an agreement between people, i.e., social reality is socially constructed. In this sense, individuals or entities act following their intersubjectively-shaped images of surrounding reality.

As Yin (2003) states, a case study design should be considered when we want to cover contextual conditions because we believe they are relevant to the phenomenon under study. The case study chosen in this article points to the impact of radio convergence on the perception of individual privacy. The social context of the case is constructed by 'actors' involved: Radio DJs and management; institutional supervisory bodies of the radio; the royal family environment and some of its members; hospital representatives.

In this article I use an 'intrinsic' type of case study. Stake (1995) suggests taking this approach "when the intent is to better understand the case...because in all its particularity and ordinariness, the case itself is of interest" (Baxter \& Jack, 2008, p. 549). According to Stake (1995), documents could be the sources of evidence. In my analysis of the Royal Prank, newspaper articles and online news were reviewed. They were retrieved from: BBC, ABC, CNN, The Guardian, Daily Mail, Daily Telegraph, and The New York Post in the period between December 2012 and December 2015. The keywords used for the search were: 'Royal Prank' and 'Jacintha Saldanha.' Furthermore, the online privacy guidelines of the British Office of Communications (Ofcom) and the Australian Communications and Media Authority (ACMA) were studied. A review of available documents was used as a data gathering tool here while its interpretation was the way to analyse the data collected. This allowed an answer to be provided for the given research questions:

Research Question 1: How did the process of creating the Royal Prank call influence its final outcome?

Research Question 2: What is the social context of radio broadcaster responsibility for the privacy of other parties?

Research Question 3: How do the privacy protections of third parties work in legal terms, with regard to radio prank calls? 


\section{The Social Context of the Royal Prank: Media Reactions before and after Jacintha Saldanha's Death}

The social reception of the Royal Prank can be divided into two stages. The first stage (until Jacintha Saldanha's suicidal note revealed) was mostly focused on the prank, Duchess Kate, and her privacy. The latter stage began with the news of a nurse's suicidal death, and from this moment the discussion shifted to her privacy and, in more general terms, to the questions of journalistic boundaries and responsibilities.

\subsection{Stage One-The Beginning}

2DayFM is a part of the SCA group that controls radio and television stations around Australia. At the time of the prank call in 2012, it was one of the most popular radio stations with 259,000 listeners (Wilding, 2015). The Royal Prank materials were recorded on the 4th of December and broadcast on-air on the 5th of December 2012. Then, the journalists themselves started promoting the recording on social media. To his 3,700 followers, Mike Christian tweeted: "Not sure how it happened, but called Kate Middleton's hospital pretending to be The Queen and they PUT US THROUGH!!" (McMillen, 2013). On Facebook, he wrote: "The only bad thing about our Royal Prank is knowing that I will NEVER EVER top this" (McMillen, 2013). Mel Greig told The Adelaide Advertiser: "This is by far the best prank I've ever been involved in....It's definitely a career highlight" (McMillen, 2013). "The hashtag \#royalprank was retweeted more than 15,000 times on Twitter after the radio station began promoting the call" (Mendoza, 2012). Within two days, at least 5,000 joke links were created on the web. "The annual turnover of SCA Company for the 2011-2012 financial year was AUD \$273.6 million (US \$247 million). The wording of that portentous SCA press release announcing the 'biggest Royal Prank ever' certainly may not have been hyperbole" (McMillen, 2013).

The Duchess's entourage accepted the joke with leniency. Just after the broadcast, a spokesman for William and Kate stated that "he would be making no comment on the hoax call" ("Royal pregnancy," 2012). Royal commentator Robert Jobson said he "did not believe the radio call had been intended as a serious invasion of (the duchess') privacy" (Mendoza, 2012). "The palace has refused to comment about the embarrassing hoax saying they were leaving responses to the hospital" (Miranda, 2012). On December 6th, two days after the joke, when asked for comment as a future grandfather, Prince Charles replied: "How do you know I'm not a radio station?" (McMillen, 2013). In other words, Prince Charles did not consider the joke a violation of the privacy of the royal family and took a rather humorous approach to the situation.

The British online press has hit an alarming tone. The press criticised presenters, demanding their dismissal and the suspension of the broadcast. Above all, however, it emphasised the demand for an apology to the Duchess "for invading her privacy so egregiously, and deceptively" (McMillen, 2013). On December 5th, The Telegraph asked the question: "How is it OK to scam a hospital into telling you about a pregnant woman's condition?...The Sun called the presenters "brazen" and The Daily Mail reported on Buckingham Palace's fury at the privacy breach" (Miranda, 2012). The overtone of the 2DayFM broadcast was pure entertainment. The Facebook post of the station under the recording told us to "listen to the prank that the world is talking about. Can you believe Mel and MC got away with these dodgy accents?" (Mendoza, 2012).

\subsection{Stage Two-Aftermath}

After the death of Jacintha Saldanha, social media was constantly duplicating updates about the prank: "The Twitter account for radio host Michael Christian (@MContheradio) had included five updates about the prank in the morning of the nurse's death....The hashtag \#royalprank continued to be used after news of the nurse's death" (Mendoza, 2012). "More than seven hours after Saldanha's death, 2DayFM's website was still plugging its royal scoop" (Rayner, 2012).

It was only Jacintha Saldanha's suicide and her farewell letter in which she blamed the presenters and demanded: "make them pay for my mortgage" (Smyth, 2013) that started the discussion about the legal context of the Royal Prank. Moreover, the legal investigations were initiated both in Great Britain and Australia. One in connection to the nurse's death was led by the coroner, and another in regard to professional standards of broadcaster and its staff was introduced by ACMA.

The Royal Prank was broadcasted without consent of the people involved-that was one of the conclusions. Rhys Holleran (chief executive of SCA) claimed that "the station had attempted to contact King Edward VII Hospital no less than five times before broadcasting" (Rayner, 2012). The hospital spokesperson accused the station, in turn, that on its behalf even a single person "did not speak to anyone in the hospital's senior management or anyone at the company that handles our media inquiries" (Rayner, 2012). The investigation showed that indeed "four calls-the longest lasting 45 secondswere made by the radio station to the hospital.... They were terminated by the recipient, who was almost certainly Saldanha" (Davies, 2014a). The coroner, during the trial following the death of Jacintha Saldanha in London, stated: "If she did take those calls, I find it inconceivable she would have consented, as a participant in the call, to its broadcast" (Davies, 2014a). One can assume that 2DayFM was only formally trying to get permission to broadcast a joke, stubbornly calling the reception of the hospital instead of trying to get through to its management. It is obvious that obtaining such permission from the hospital as an institution of social trust was impossible. John Lofthouse, the hospital's chief executive, stated: 
"This was a foolish prank call that we all deplore...it was technically...a breach of patient [Duchess] confidentiality" ("Royal pregnancy," 2012).

The British Daily Mail, quoting the Indian press, reported that "Jacintha Saldanha had attempted suicide twice before...during a family visit to India" (Taher, 2012). The owner of 2DayFM-SCA-published a statement stating that "neither police nor the hospital had publicly blamed the radio station for Saldanha's death" (Mendoza, 2012). But the nurse realized that the whole world knew about the joke: "A police search of her laptop showed she researched suicide prevention sites, and news reports of the hoax" (Davies, 2014a). Saldanha did not have the courage to appear at work: "I don't know how to face the bosses tomorrow. I feel so ashamed of myself" (Davies, 2014b). She couldn't even talk to her husband about it: "They spoke several times that week, but she did not tell him or the kids anything about it" (Palmeri, 2012). Jacintha Saldanha's emails disclosed during the investigation testify that she was overwhelmed with responsibility for her friend to whom she transferred the received prank call: "It's all my fault and I feel very bad about this getting you involved....At the moment in time, with that voice, I couldn't even think of anything else" (Davies, 2014a). Jacintha Saldanha was afraid of professional consequences, too. She wrote to her superior: "I feel very sorry for breaking security, I am ready for any punishment" (Davies, 2014a). Chief executive of the hospital John Lofthouse condemned the joke, stating that "nurses were trained to care for people, not to cope with journalistic trickery" (Rayner, 2012), but there was no public stance of superiors. Lofthouse also commented that "some senior managers thought both nurses should be disciplined, but his view, and that of the matron, was that the nurses were victims and categorically they would not be disciplined" (Davies, 2014b). As the investigation showed, the supervisor did not find time to reply to the emails of the concerned nurse (Davies, 2014b).

\section{Modern Radio Production and the Politics of Privacy Protection}

On modern radio in democratic countries, the policy of privacy harmonises with the principles of the liberal or democratic corporatism model of Hallin and Mancini (2004, pp. 34-35). According to this model, autonomy is a key determinant of professional journalists. They should achieve the highest standards through selfimprovement and have responsibility for the accuracy of published content. However, it should take into account the fact that media products are often the result of collective actions. That, to some extent, may disturb the autonomy of individuals. Journalistic autonomy is determined at the legislative level of a country, through legal acts like media law, legal regulations for broadcasters, etc. On a lower level of co-regulation, the creation of norms is done with active participation (between) the state organizations and media/owner. In addition to these guidelines, radio stations may (but do not have to) draw up internal editorial rules: self-regulation, that require journalistic diligence to comply with good radio practices (Dobek-Ostrowska, 2019, pp. 48-49). This strategy is a well-known voluntary form of "employing ethics in practice in journalistic groups, mainly associated with television, radio, the Internet, social media, advertising, etc. Media institutions freely and upon their own initiative, impose restrictions on themselves or adopt rules of conduct" (Jakubowicz \& Sükösd, 2008, p. 37). In many countries around the world the radio market consists of three sectors: private, public, and community. On one hand, this diversity supports the autonomy of journalists, but on the other, it restrains some of this diversity. This results from the differences in political systems, cultures, or the development of civil society. Restrictions on journalistic autonomy arising from the commercial nature of radio stations, in which employees primarily seek for an attractive content, are particularly important. In the case of commercial broadcasters, there is a preference towards financial factors in broadcasting policies. Therefore, the protection of privacy under self-regulation may be difficult, due to the tabloid model of communication. Following controversial, sensational and entertainment themes does not go hand in hand with applying internal restrictions in the form of a code of ethics.

Especially at the self-regulation level, radio stations are guided by principles consistent with the program strategy and institutional interest. In the case of commercial stations, especially those which are elements of media corporations (such as 2DayFM), the decisive factor is the attractiveness of the message and its 'market' potential. The message becomes a product for sale. In the era of converged radio, the Royal Prank could function as a web podcast. The Royal Prank was recorded, reedited, and then put on broadcast on Hot 30 Countdown six hours after the phone call to the hospital had been made. The Royal Prank was a ripped fragment of the broadcast. The act of recording material by journalists and its post-production were separated. "The call was established by the station's PAPX system, linked to the studio via an answering device known as Phone Box, then recorded and played out through equipment known as Voxpro" (Wilding, 2015). Because the prank itself fit the call-joke genre, and its content was very attractive, it became part of the broadcast of Hot 30 Countdown, which was very popular among listeners.

The fragmentation of the original broadcast and its promotion have important implications in the context of privacy policy. Each radio station should obtain permission from a person whose voice is used in the recorded material prior to its broadcasting. In case of radio quiz shows and competitions, the listeners first agree to the recording and its use (including online and on-demand channels without time restrictions).

During their live program, the pair of DJs-Greig and Christian-broadcast a fragment (the Royal Prank) which 
was edited by someone else. In this way, adequate protection of the privacy of individuals affected by the prank was not within their responsibility. The responsibility was taken over by station lawyers, who allowed the broadcast to take place, ignoring Mel Greig's doubts, who admitted that she should have "tried harder to stop the prank from airing" (Davies, 2014a). At the same time, Greig confirmed her own thoughtlessness of the participant in the process of 'external' radio production, i.e., previously recorded and subject to post-production before being broadcast on air: "There's a whole team of people that work with us. We just go on and keep recording stuff or doing other prep....We do that and leave it for everybody else to deal with" ("Royal prank scandal," 2013).

The presenters of the Royal Prank themselves primarily lacked 'soft' guidelines for ethical behaviour at work. The 2DayFM station naively explained: "they fully expected hospital staff to hang up on them within seconds after picking up on their 'silly English accents"' (Duell, Andrews, Greenhill, Shears, \& English, 2012). Mel stated that "we obviously wanted it to be a joke" (Duell et al., 2012). Mel and Mike however, lacked journalistic reflection, which should stop them from making a phone call to the hospital for a joke, where the Duchess was concerned about the fate of her early pregnancy, and was additionally overwhelmed with the expectations of her as the mother of the future heir to the throne. Self-regulation principles would require interrupting the conversation and revealing the perpetrators of the joke at the right moment of the recording. From an ethical perspective, it seems obvious that the DJs should have stopped the conversation before the nurse revealed the intimate details of Duchess Kate's well-being. One can assume that they did not reveal themselves, because they did not feel that they had crossed any ethical boundaries. They lacked a self-regulation ethics code that required moral virtues. Virtue ethics thereby foregrounds the importance of "moral wisdom...and the questions of what sort of person I should be" (Ess, 2013, p. 241). Instead, private information on patient care was disclosed, which resulted in media around the world buying the Royal Prank. Thus, the joke became a scandal because it forced the institutional response of the hospital, defending itself against allegations of poor protection of patient safety. And since there was a protocol of conduct in this case, Jacintha Saldanha, who broke it and switched the call without verifying the phone number was first to blame, although the media did not make such a statement explicitly.

As a result of an investigation of ACMA it turned out that 2DayFM broke the 'commercial radio code of practice' in Australia (Wilding, 2015). This rule also applies in the British broadcasting law, including in the Communications Act of 2003 and the Broadcasting Act of 1996 (Ofcom, 2017). The station intentionally broke the commercial radio code:

By broadcasting the words of identifiable persons in circumstances where those persons: were not in- formed in advance that their words may be broadcast, would not have been aware that their words may be broadcast, did not give their consent to the broadcast of the words. (Wilding, 2015)

The station's decision to broadcast the Royal Prank without the consent was therefore a play with privacy policy. A media law specialist at Sydney University, Professor Barbara McDonald, said that "2DayFM knew they should be getting consent (to air the interview) and they failed to. It almost showed they knew (what) they had to and they didn't and then they decided to run the risk" (Rourke, 2012). The aforementioned decision not only violated the law, but also Jacintha Saldanha's personal rights. The presenters joke provoked her improper professional behaviour, exposing her to the consequences from her employer. ACMA, in a report published on 20th April 2015, investigating whether the broadcaster had committed an offence that violated the terms of its licence, stated:

The broadcast used the deception of the prank to engage with the Employees in a way that was personally degrading and humiliating and was likely to reduce their professional standing....Even if the material obtained as a result of the prank was unexpected, once it was obtained the decision to broadcast itsome four and a half hours after it was recordedwas made deliberately by the licensee and in circumstances in which the licensee could have assessed the likely impact of its broadcast on the Employees. (Wilding, 2015)

The prank jeopardised the nurses' good name as "their voices were clearly audible...the content broadcast was...highly newsworthy and its publication detrimental to the interests of the employees, the employees were identified by the hospital because of the prank call" (Wilding, 2015).

However, in ACMA's opinion, 2DayFM did not break the 'privacy code' because:

There was no breach of the rule regarding offence against 'generally accepted standards of decency'.....Nor did it breach the rule concerning the use of 'material relating to a person's personal or private affairs, or which invades an individual's privacy.' The privacy rule only applies to news and current affairs programs and the ACMA agreed with 2DayFM that Summer 30 was not such a program. (Wilding, 2015)

The legal loophole in the 2DayFM privacy policy is therefore due to the nature of the entertainment program, although it is difficult to understand the selective treatment of the individual's rights to protect his or her privacy.

ACMA approved the legal provision about the lack of privacy protection of entertainment program participants, although 2DayFM repeatedly violated the code of 
good practice. It was reprimanded by a government supervisory body in 2009, after "a 14-year-old girl, brought on the show by her mother, was attached to a lie detector during a live broadcast and asked if she was having sex. She revealed that she had been raped" (Lyall, 2012). In turn, in 2011, "one of its hosts called a journalist a 'fat slag' and threatened her on the air" (Lyall, 2012). None of these offences ended in revoking of licenses for this type of 'entertainment.'

The station did not suffer any legal sanctions in connection with the emission of the Royal Prank. The ACMA only concluded that:

The station will require all presenters, production and management staff to undergo a training program on their ethical and legal obligations....A further license condition has also been applied for three years, ensuring the station does not broadcast the words of an identifiable person unless they've been informed in advance. (Whitbourn \& Lallo, 2015)

\section{Conclusions}

The case study of Royal Prank illustrates three aforementioned main issues with implications for the privacy protection. First, it is the technical aspect or digitization of radio content and convergence with other media. Then, there is division of radio-related labour, leading to a lack of professional responsibility for respecting privacy standards. Last but not least, there is a lack of proper legal tools to deal with the deficiencies in privacy protection, which are brought by the first two factors. In the case of the Royal Prank all of them result in the impossibility to protect individual privacy of a person who is unintentionally involved in a radio show.

\subsection{Technology and Convergence}

The study points to the impact of radio convergence on the perception of individual privacy. The podcast nature of broadcasting in convergent radio means that it reaches 'beyond the radio,' to random online recipients as an abstracted fragment of a radio show. It gains 'an afterlife' on the Internet. The sound is provided with the images of the presenters in the studio and placed on social media to entertain the audience, at the price of discrediting people who are treated merely as the unaware figures playing their parts for the benefit of the show. The case uncovers the loss of editorial control over the program and lack of journalists' responsibility for the final outcome. The case also shows how duplicating previously recorded excerpts on the Internet opens the space for violating the individual's right to privacy.

\subsection{Radio Production}

The case study shows how the actions of both Radio DJs and management evoked mediatised reactions of institutional supervisory bodies of the radio, the Royal Family environment and hospital representatives. The Australian presenters were tempted to extend the prank's conversation and make it more attractive for social media. Self-regulation principles would require interrupting the conversation and revealing the perpetrators of the joke at the right moment of the recording. Due to this fact, the interrogated nurse could not react spontaneously and laugh (or not) at the joke along with others. She could not play a part in the game on equal terms. The radio and other media constructed the social context of the Royal Prank, where Jacintha Saldanha's 'right to be forgotten' was not respected. Repeating the Royal Prank in social media and discussing it via online media, on one hand ridiculed Jacintha Saldanha's language skills as an immigrant from India, on the other unintentionally emphasised her breaking the protocol. In a social context, Jacintha Saldanha was indirectly stigmatised for her violation of professional ethics.

\subsection{Legal Issues}

The next step of the research was the interpretation of 2DayFM actions from the perspective of commercial radio legislation. That let the gaps in Jacintha Saldanha's privacy protection be exposed. 2DayFM broke the 'commercial radio code of practice' by broadcasting the prank without the consent of parties involved. Unaware people are recorded and drawn into the plot. Separating the process of recording and broadcasting material, frees journalists from responsibility for what they say on air. During the investigation, ACMA stated that 2DayFM did not break the 'privacy code' because of the entertaining convention of the Hot 30 Countdown. The lack of sufficient privacy protection for people who appear in the entertainment programs of commercial radio is the main negligence here. In the absence of their clear permission, the 'privacy code' should apply the same restrictions as in the case of news and current affairs programs. The position of the investigating authorities did not contain any indications for further action. The Crown Prosecution Service for England and Wales stated that "no further investigation is required because any potential prosecution there would not be in the public interest" (Wilding, 2015). In addition, the New South Wales Police Force and the Australian Federal Police, as a result of joint actions "found no breach of the Surveillance Devices Act 2007, the Telecommunications (Interception and Access) Act 1979, or any other Act" ("London hospital prank," 2015). These statements maintained the status quo in the Australian Privacy Policy for commercial radio in the form of the provision as "some codes offer express privacy protections only in the context of news and current affairs broadcasts" (ACMA, 2016). Among them is also the Commercial Radio Code of Practice and the Subscription Narrowcast Radio Code of Practice. 


\subsection{Summary}

Radio convergence provided 2DayFM with new tools to make a more attractive product and then sell it across many platforms. At the same time, it multiplied the damage to Jacintha Saldanha's privacy. The tragic finale fostered the investigations, but all the noted violations did not result in legal consequences for the parties involved.

The case of the Royal Prank also demonstrates a decrease of on-air intimacy and growing distance between the presenters and their audience. The Royal Prank is something more than just an isolated case of a radio prank. It illustrates the fragility of unintentionally involved humans who serve as mere puppets for the sole purpose of entertainment created by powerful media platforms.

\section{Conflict of Interests}

The author declares no conflict of interests.

\section{References}

Ala-Fossi, M. (2016). Why did TV bits and radio bits not fit together? Digitalization and divergence of broadcast media. In A. Lugmayr \& C. Dal Zotto (Eds.), Media convergence handbook-Vol. 1: Journalism, broadcasting, and social media aspects of convergence (pp. 265-285). Berlin Heidelberg: Springer.

Australian Communications and Media Authority. (2016). Privacy guidelines for broadcasters. Canberra: Australian Communications and Media Authority.

Baxter, P., \& Jack, S. (2008). Qualitative case study methodology: Study design and implementation for novice researchers. The Qualitative Report, 13(4), 544-559. Retrieved from http://www.nova.edu/ ssss/QR/QR13-4/baxter.pdf

Berry, R. (2006). Will the iPod kill the radio star? Profiling podcasting as radio. Convergence, 12(2), 43-162.

Berry, R. (2016). Part of the establishment: Reflecting on 10 years of podcasting as an audio medium. Convergence: The International Journal of Research into New Media Technologies, 22(6), 661-671.

Bonini, T. (2015). The 'second age' of podcasting: Reframing podcasting as a new digital mass medium. Quaderns del CAC, 41(18), 21-30.

Couldry, N. (2014). Mediatization: What is it? In L. Kramp, N. Carpentier, A. Hepp, I. Tomanić Trivundža, H. Nieminen, R. Kunelius ... R. Kilborn (Eds.), Media practice and everyday agency in Europe (pp. 33-39). Bremen: Edition Lumière.

Davies, K. (2014a, September 11). Jacintha Saldanha 'took blame' for Duchess of Cambridge prank call. The Guardian. Retrieved from https://www.theguardian. com/world/2014/sep/11/jacintha-saldanha-tookblame-prank-call-duchess-cambridge-australian-djsinquest

Davies, K. (2014b, September 12). DJ apologises to
Jacintha Saldanha's family as nurse's death ruled suicide. The Guardian. Retrieved from https://www. theguardian.com/world/2014/sep/12/jacinthasaldanha-death-suicide-prank-call-dj-apologises

de Sola Pool, I. (1983). Technologies of freedom: On free speech in an electronic age. Cambridge, MA: Belknap Press and Harvard University Press.

Dobek-Ostrowska, B. (2019). Polish media system in a comparative perspective. Berlin: Peter Lang.

Douglas, S. J. (2002). Letting the boys be boys: Talk radio, male hysteria, and political discourse in the 1980s. In M. Hilmes \& J. Loviglio (Eds.), Radio reader: Essays in the cultural history of radio (pp. 485-505). New York, NY and London: Routledge.

Dubber, A. (2013). Radio in the digital age. Cambridge: Polity Press.

Duell, M., Andrews, E., Greenhill, S., Shears, R., \& English, R. (2012, December 10). We're both shattered. My first thought was: Is she a mother? Radio hosts at centre of prank give self-pitying interviews. Daily Mail. Retrieved from https://www.dailymail. co.uk/news/article-2245727/Mel-Greig-MichaelChristian-interview-Were-shattered--thought-Ismother.html

Dwyer, T. (2015). Convergent media and privacy. New York, NY: Palgrave Macmillan.

Eisenhardt, K. M. (1989). Building theories from case study research. The Academy of Management Review, 14(4), 532-550.

Ess, C. (2013). Digital media ethics (2nd ed.). Oxford: Polity Press.

Fickers, A. (2006). National barriers for an imag(e)ined European community: The technopolitical frames of postwar television development in Europe. In L. Hojbjerg \& H. Sondergaard (Eds.), European film and media culture, northern lights, film and media studies yearbook 2005 (pp. 15-36). Copenhagen: Museum Tusculanum Press.

Habermas, J. (1996). Between facts and norms: Contributions to a discourse theory of law and democracy. Cambridge, MA: MIT Press.

Hallin, D. C., \& Mancini, P. (2004). Comparing media systems: Three models of media and politics. New York, NY: Cambridge University Press.

Horton, D., \& Wohl, R. (1956). Mass communication and para-social interaction: Observations on intimacy at a distance. Psychiatry, 19(3), 215-229.

Jakubowicz, K., \& Sükösd, M. (2008). Twelve concepts regarding media system evolution and democratization in post-communist societies. In K. Jakubowicz \& M. Sükösd (Eds.), Finding the right place on the map: Central and Eastern European media change in a global perspective (pp. 9-40). Bristol and Chicago, IL: Intellect Books.

Jenkins, H. (2003). Transmedia storytelling. MIT Technology Review. Retrieved from https://www. technologyreview.com/2003/01/15/234540/ transmedia-storytelling 
Jenkins, H. (2008). Convergence culture: Where old and new media collide. New York, NY: University Press.

Köchler, H. (2017). Idea and politics of communication in the global age. In M. Friedrichsen \& Y. Kamalipour (Eds.), Digital transformation in journalism and news media media management: Media convergence and globalization (pp. 7-15). Berlin: Springer.

Kubitschko, S., \& Kaun, A. (Eds.). (2016). Innovative methods in media and communication research. Cham: Palgrave Macmillan.

Laville, S., \& Davies, C. (2012, December 13). Jacintha Saldanha suicide note criticised hospital staff. The Guardian. Retrieved from www.theguardian.com/ world/2012/dec/13/jacintha-saldanha-suicide-notes

London hospital prank: High Court backs authority's power to find 2Day FM radio presenters broke law. (2015, March 4). ABC News. Retrieved from https://www.abc.net.au/news/2015-03-04/highcourt-backs-acmas-power-to-find-2day-fm-brokelaw/6279276

Lyall, S. (2012, December 7). Prank call seeking royal family secrets takes horrifying turn. The New York Times. Retrieved from https://www.nytimes.com/ 2012/12/08/world/europe/nurses-death-stirssharp-criticism-of-royal-prank-call.html

McHugh, S. (2012). Oral history and the radio documentary/feature: Introducing the "COHRD" form. Radio Journal: International Studies in Broadcast and Audio Media, 10(1), 35-51.

McMillen, A. (2013, August 2). The Royal Prank: The story behind the worst radio stunt in history. BuzzFeed. Retrieved from https://www.buzzfeed.com/ andrewmcmillen/the-royal-prank-how-a-crank-callbecame-a-tragedy

Meier, K. (2007). Innovations in Central European newsrooms: Overview and case study. Journalism Practice, 1(1), 4-19.

Mendoza, D. (2012, December 11). Social media entwined in radio prank, nurse death. CNN. Retrieved from https://edition.cnn.com/2012/12/07/tech/ social-media/radio-prank-suicide-social-media/ index.html

Miami radio fined for Castro hoax. (2004, April 25). BBC News. Retrieved from http://news.bbc.co.uk/2/hi/ americas/3657499.stm

Miles, M. B., \& Huberman, A. M. (1994). Qualitative data analysis: An expanded source book ( $2 \mathrm{nd}$ ed.). Thousand Oaks, CA: Sage

Miranda, C. (2012, December 6). Aussie radio hosts sorry for pretending to be Queen and Prince Charles in call to Kate's hospital. The Advertiser. Retrieved from https://www.adelaidenow.com.au/news/aussieroyal-radio-hoax-condemned/news-story/ 5b73e23a4e7c73df3aad351127693d54

Ofcom. (2017). Section eight: Privacy. Ofcom. Retrieved from https://www.ofcom.org.uk/tv-radio-and-ondemand/broadcast-codes/broadcast-code/sectioneight-privacy
Palmeri, T. (2012, December 24). Nurse who killed herself after Kate Middleton hoax attempted suicide twice before. The New York Post. Retrieved from https://nypost.com/2012/12/24/nurse-who-killedherself-after-kate-middleton-hoax-attemptedsuicide-twice-before

Peters, J. D. (1997). Realism in social representation and the fate of the public. The Public, 4(2), 5-16.

Preston, P. (2009). Making the news. London: Routledge.

Preston, P., \& Rogers, J. (2013). Convergence, crisis and the digital music economy. In S. Diehl \& M. Karmasin (Eds.), Media and convergence management (pp. 247-261). Berlin Heidelberg: Springer.

Rayner, G. (2012, December 8). 'Cruel' hospital hoax still playing on radio. The Daily Telegraph. Retrieved from https://www.telegraph.co.uk/news/9731359/ Cruel-hospital-hoax-still-playing-on-radio.html

Rourke, A. (2012, December 10). Royal hoax station tried to contact hospital before broadcast. The Guardian. Retrieved from https://www.theguardian.com/ uk/2012/dec/10/royal-hoax-station-contactedhospital

Royal prank scandal: DJ Mel Greig settles dispute, resigns. (2013, December 5). ABC News. Retrieved from https://www.abc.net.au/news/2013-12-05/royalprank-call-dj-settles-dispute-with-station/5138650

Royal pregnancy: Hoax call fools Duchess of Cambridge hospital. (2012, December 5). BBC News. Retrieved from https://www.bbc.com/news/uk-20610197

Searle, J. R. (1995). The construction of social reality. New York, NY: Free Press.

Silverstone, R. (1995). Convergence is a dangerous word. Convergence: The international journal of research into new media technologies, 1(1), 11-13.

Singer, J. B. (2004). Strange bedfellows? The diffusion of convergence in four news organizations. Journalism Studies, 5(1), 3-18.

Smyth, S. (2013, April 28). Jacintha Saldanha suicide note over Kate Middleton hospital prank call: 'Holds radio DJs responsible.' Daily Mail. Retrieved from www.dailymail.co.uk/news/article-2316055/ Jacintha-Saldanha-suicide-note-Kate-Middletonhospital-prank-holds-radio-DJs-responsible.html

Sousa, M. N., Martins, M. L., \& Zagalo, N. (2016). Transmedia storytelling: The roles and stakes of the different participants in the process of a convergent story, in divergent media and artefacts. In A. Lugmayr, C. Dal Zotto (Eds.), Media convergence handbookVol. 2: Firms and user perspectives (pp. 117-137). Berlin Heidelberg: Springer.

Stachyra, G. (2017). Podcasting as audio technology. Development prospects. Media Studies, 68(1), 1-17.

Stake, R. E. (1995). The art of case study research. Thousand Oaks, CA: SAGE.

Taher, A. (2012, December 22). Royal nurse found hanged after taking DJs' hoax call about pregnant Duchess of Cambridge had tried to kill herself twice before last year. Daily Mail. Retrieved from 
https://www.dailymail.co.uk/news/article2252290/Jacintha-Sadanha-Nurse-answered-hoaxDuchess-Cambridge-attempted-kill-before.html

Tavani, H. (2013). Ethics and technology: Controversies, questions, and strategies for ethical computing (4th ed.). Hoboken, NJ: Wiley.

Tellis, W. (1997). Introduction to case study. The Qualitative Report, 3(2). Retrieved from http://www.nova. edu/ssss/QR/QR3-2/tellis1.html

Whitbourn, M., \& Lallo, M. (2015, July 17). Royal prank call: 2DayFM hit with tighter licence conditions. The Sydney Morning Herald. Retrieved from https://www.smh.com.au/national/royal-prank- call-2dayfm-hit-with-tighter-licence-conditions20150717-gieel0.html

Wilding, D. (2015). The summer 30 royal prank call: Outcomes for Australian broadcasting regulation. Journal of Media Law, 7(1), 92-107.

Yazan, B. (2015). Three approaches to case study methods in education: Yin, Merriam, and Stake. The Qualitative Report, 20(2), 134-152. Retrieved from http:// www.nova.edu/ssss/QR/QR20/2/yazan1.pdf

Yin, R. K. (2002). Case study research: Design and methods. Thousand Oaks, CA: Sage.

Yin, R. K. (2003). Case study research: Design and methods (3rd ed.). Thousand Oaks, CA: Sage.

\section{About the Author}

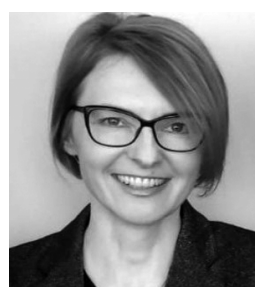

Grażyna Stachyra, (PhD in Media Communication) is Associated Professor at Maria Curie-Skłodowska University in Lublin. She is former Vice-Chair of ECREA's Radio Research Section and Co-Editor of Radio: The Resilient Medium (Sunderland, 2014), Radio Relations: Policies and Aesthetics of the Medium (Cambridge Scholars Publishing, 2018). She is also Author and Co-Author of various articles dedicated to radio i.e., The Radio Plays Games (EJC, 2012), Radio in the Workplace: A Liminal Medium between Work and Leisure (Media Culture \& Society, 2015), Radio-Bodies as a Claim for Freedom: The Imagined Public Medium at the Majdanek Concentration Camp (Media Culture \& Society, 2019). 